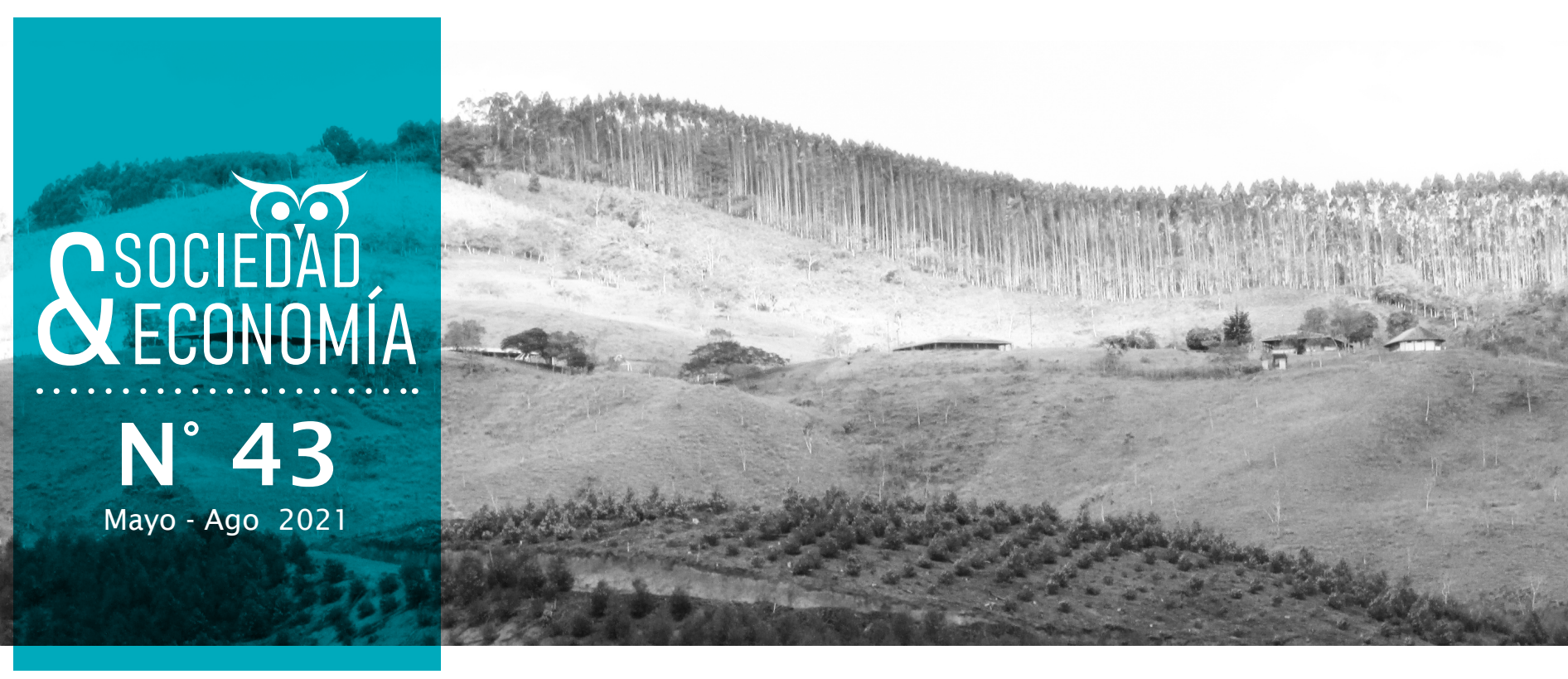

\title{
Mecanismos de coordinación en la planificación de cuencas hidrográficas en Colombia: el caso del río Dagua
}

Coordination Mechanisms in the Watershed Planning in Colombia: The Case of the Dagua River

Marco Antonio Aguirre' Universidad del Valle, Cali, Colombia.

@ marco.aguirre@correounivalle.edu.co

(1) https://orcid.org/0000-0002-5198-1748

Oscar Buitrago-Bermúdez ${ }^{2}$

Universidad del Valle, Cali, Colombia.

@ oscar.buitrago@correounivalle.edu.co

(1) https://orcid.org/0000-0002-1726-9888

Francy Viviana Bolaños-Tróchez ${ }^{3}$ Universidad del Valle, Cali, Colombia.

@ francy.bolanos@correounivalle.edu.co

(1) https://orcid.org/0000-0001-8317-3553

Recibido: 19-03-2020

Aceptado: 07-1 1-2020

Publicado: 01-05-2021

1 Geógrafo.

2 Doctor en Geografía.

3 Geógrafa. 


\title{
Resumen
}

En Colombia, la planificación de cuencas hidrográficas es orientada por políticas espaciales, en las cuales se definen principios, objetivos, estrategias e instrumentos de gestión ambiental y territorial del país para garantizar la coordinación interinstitucional, aprovechamiento y uso sostenible de sus recursos naturales como son agua y suelo. Este contexto permite tomar como caso de estudio la cuenca hidrográfica del río Dagua, localizada en la vertiente Pacífico de la Cordillera Occidental, en el departamento del Valle del Cauca, Colombia, donde se analiza la aplicabilidad de los mecanismos e instrumentos de planificación del Estado y sus instituciones en la gestión interinstitucional de una de las cuencas más importantes del país. Metodológicamente, se emplearon técnicas cualitativas como la revisión documental, entrevistas con agentes sociales y análisis de contenido. Los resultados evidencian debilidades en la coordinación y articulación de dichos instrumentos con repercusiones significativas en el estado ambiental actual de la cuenca.

Palabras clave: estado moderno; políticas ambientales y territoriales; cuenca hidrográfica; río Dagua.

\begin{abstract}
In Colombia, watershed planning is guided by spatial policies, in which it defines principles, objectives, strategies, and instruments of environmental and territorial management of the country to guarantee territorial management of the country to ensure interinstitutional coordination, exploitation and sustainable use of its natural resources such as water and soil. This context allows to take as a study case the watershed of the Dagua River, located on the Pacific slope of the Western Cordillera, in the Department of Valle del Cauca, Colombia, where the applicability of the planning mechanisms and instruments of the State and its institutions in the interinstitutional management of one of the most important basins in the country is analyzed. Methodologically, qualitative techniques such as document review, interviews with social agents and content analysis were used. The results show weaknesses in the coordination and articulation of these instruments with significant repercussions on the current environmental status of the basin.
\end{abstract}

Keywords: Modern state; environmental and territorial policies; watershed; Dagua River.

\section{Finaciación}

El artículo hace parte de los resultados del proyecto de investigación titulado Estrategias para la recuperación y manejo integrado del recurso hídrico en las cuencas del Cauca y Dagua en el Valle del Cauca, financiado por el Fondo de Ciencia, Tecnología e Innovación del Sistema General de Regalías (FNR) y coordinado por la Universidad del Valle (2015 -2019).

\section{Conflicto de interés}

Los autores declaran no tener ningún conflicto de interés en la publicación de este artículo.

\section{Este trabajo está bajo la licencia Atribución-No-Comercial 4.0 Internacional}

¿Cómo citar este artículo?

Aguirre, M. A., Buitrago-Bermúdez, O. y Bolaños-Tróchez, F. V. (2021). Mecanismos de coordinación en la planificación de cuencas hidrográficas en Colombia: el caso del río Dagua. Sociedad y economía, (43), e1019207. https://doi.org/10.25100/sye.v0i43.9207 


\section{Introducción}

La cuenca hidrográfica del río Dagua se localiza en el Departamento del Valle del Cauca, Colombia, sobre la vertiente del Océano Pacífico (ver Figura 1). Representa un anclaje espacial clave para la economía de Colombia, ya que en ella se localiza el principal puerto marítimo a nivel nacional, en el municipio de Buenaventura. Cuenta con un área aproximada de 142.200,18 ha, y se divide en dos partes: cuenca alta y cuenca baja. Es un ecosistema de interés regional, por ser una de las mayores productoras de agua. En su parte alta, la precipitación oscila entre los 900 y $1.600 \mathrm{~mm} / a n ̃ o$, mientras en su parte baja se distinguen rangos entre 6.000 y 8.000 mm/año. Elementos que, asociados a su geomorfología estructural, caracterizada por altas pendientes con cambios abruptos, contribuyen al proceso de erosión natural del suelo, el cual se ha consolidado como uno de los principales problemas en la cuenca, debido a la sedimentación generada sobre el principal puerto marítimo del país (López y González, 2016).

A través de estudios realizados por Aguirre et al. (2017), Buitrago et al. (2019), Universidad del Valle (2016; 2017), Gamboa (2018), y Rojas y Campo (2018), se ha identificado una serie de actividades económicas de tipo agropecuario, forestal, recreativas y mineras en la cuenca. Cuya intensificación en las dos últimas décadas ha agudizado los procesos erosivos del suelo, el deterioro de fuentes hídricas, pérdida de bosques y biodiversidad, debido a la ampliación de la frontera agrícola y fragmentación de la propiedad de la tierra para construcción de condominios campestres y vivienda dispersa. Por otra parte, se ha identificado que en dicha situación intervienen agentes sociales como: 1) gremios empresariales dedicados a la explotación forestal, minería y agricultura semitecnificada; 2) instituciones del Estado; 3) sociedad civil representada por comunidades indígenas, afrodescendientes y organizaciones no gubernamentales por la defensa del medio ambiente, entre otras; y 4) usuarios del agua, representados por asociaciones de pequeños y medianos campesinos.

En la cuenca, tienen jurisdicción siete municipios: Dagua, Buenaventura, La Cumbre, Restrepo, Vijes, Yotoco y Calima Darién. Además, en ella confluyen entidades territoriales de pueblos ancestrales como son comunidades indígenas y afrocolombianas, las cuales cuentan con instrumentos de planificación territorial, así como de desarrollo social y económico, que deben articularse paralelamente a los lineamientos propuestos en instrumentos de gestión ambiental del país; como son planes de manejo y ordenamiento de cuencas hidrográficas, que aún no se consolidan en el área de estudio.

Los Municipios cuentan con Planes de Ordenamiento Territorial reglamentados por la Ley 388 (Congreso de la República de Colombia, 1997), y Planes de Desarrollo reglamentados por la Ley 152 (Congreso de la República de Colombia, 1994), que orientan objetivos de gobierno. Por su parte, las comunidades ancestrales tienen, como instrumentos de planificación territorial y ambiental, los Planes de Vida (pueblos indígenas), y Planes de Etnodesarrollo y de Manejo Ambiental (comunidades afrodescendientes). Dichos instrumentos buscan proteger y preservar la cultura y costumbres ancestrales (Tangarife y Villaquirá, 2016). Por otro lado, la Ley 99, mediante la cual se organiza el Sistema Nacional Ambiental de Colombia (SINA), menciona que los planes, programas y proyectos ambientales elaborados por entidades territoriales del Estado deben realizarse, garantizando la coherencia y armonía de los planes descritos anteriormente (Congreso de la República de Colombia, 1993b).

Desde esta perspectiva, el presente artículo busca analizar el nivel de articulación entre instrumentos de gestión territorial y ambiental, implementados por entidades territoriales con jurisdicción en la cuenca hidrográfica del río Dagua, para identificar procesos de coordinación entre objetivos y estrategias que, concertadamente, permitan generar soluciones a problemas comunes entre los municipios, y así mejorar las condiciones ambientales en la cuenca hidrográfica. La investigación tuvo como hipótesis inicial que la articulación entre instrumentos de gestión ambiental, a nivel municipal, no respondía a las actuales condiciones ambientales de la cuenca. Se realiza considerando que Colombia, como 
Sociedad y Economía N 43 (Mayo - Ago 2021) / e-ISSN: 2389-9050 / e1019207

Marco Antonio Aguirre, Oscar Buitrago-Bermúdez y Francy Viviana Bolaños-Tróchez

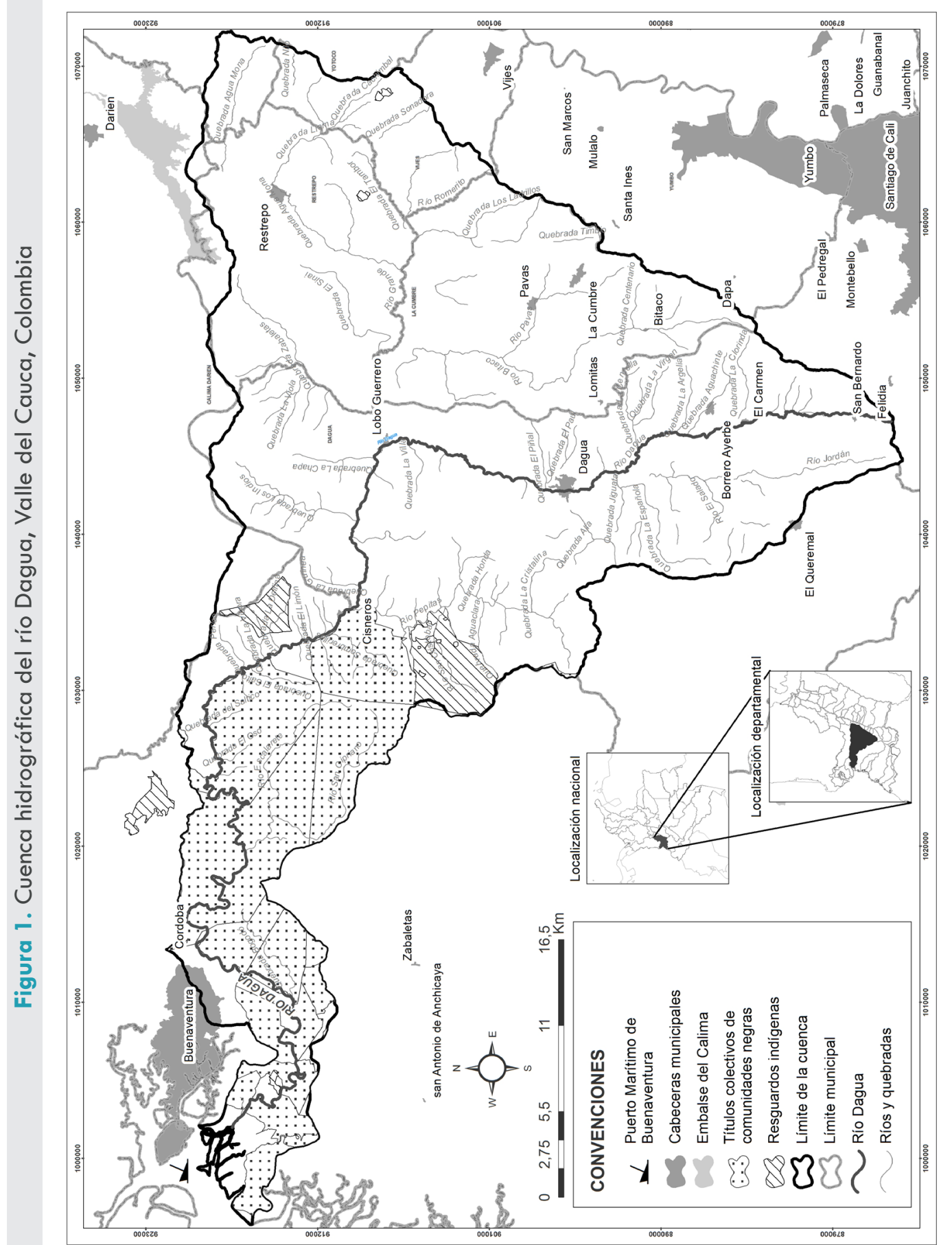


Estado social de derecho y en ejercicio de su poder político, concibe políticas y normas, con el fin de garantizar su territorialidad y propender por la gestión y planificación pública, bajo principios de articulación y coordinación (Buitrago, 2016).

\section{Metodología}

Es una investigación de corte cualitativo. Contempla revisión documental, entrevistas semidirigidas con algunos agentes sociales clave y técnicas de triangulación de entrevistas. La revisión documental se aplicó a instrumentos de gestión en la cuenca como son planes de ordenamiento territorial, correspondientes a cada uno de los municipios, planes de desarrollo, el Plan de Gestión Ambiental Regional del Valle del Cauca 2002-2012 y planes de vida de comunidades indígenas y afrodescendientes, asentadas en el área de estudio. Para ello, se construyeron categorías de análisis, orientadas al manejo ambiental y mejoramiento de servicios públicos de acueducto y alcantarillado. Respecto a la revisión del PGAR, se tuvo en cuenta el plan asignado para 2002 a 2012 por dos razones: primero, los POT de los municipios de estudio se elaboraron para ese periodo (instrumentos relativamente nuevos en Colombia); y segundo, al momento del estudio, el actual PGAR (2015-2036) se encontraba en su fase de diagnóstico y ajustes.

Esta información fue sintetizada en cuadros o matrices de doble entrada, con el fin de facilitar la interpretación de objetivos y estrategias que asumieron los municipios para la intervención y manejo ambiental de la cuenca, bien sea a nivel individual o colectivo. Se analizó mediante la técnica de análisis de información (Cáceres, 2003). Según Álvarez-Gayou (2012), para su aplicación se debe tener la información sistematizada u organizada en bases de datos y por categorías. Su análisis contempla la comparación de palabras clave (o por las categorías definidas previamente), buscando tendencias y patrones en los discursos.

Así mismo, se diseñaron y aplicaron entrevistas semi-dirigidas (Létourneau, 2009), con agentes sociales claves seleccionados mediante un muestreo teórico. Con las entrevistas, se buscó contrastar la eficacia de los instrumentos de planificación con la realidad de la cuenca descrita por los agentes sociales. En ese sentido, se preguntó por la eficacia de los instrumentos y la percepción de los agentes frente al estado ambiental de la cuenca. Este elemento es un aspecto adicional para comprobar el objetivo del artículo.

Cabe destacar que, para el siguiente ejercicio investigativo, se trabajó con los principales cinco municipios de mayor área representativa en la cuenca, los cuales son Dagua, Restrepo, La Cumbre, Vijes y Buenaventura, que ocupan el $95 \%$ ( 136.000 has) y localizan sus centros poblados al interior de esta. El municipio de Dagua es el municipio con mayor área en la cuenca.

\section{Elementos conceptuales}

La conceptualización fundamental para interpretar la aplicabilidad de los mecanismos e instrumentos de planificación del Estado y sus instituciones -en la gestión interinstitucional en cuencas hidrográficas- corresponde al concepto de poder político del Estado nacional moderno, expresado en la institucionalidad y normas, y su relación con los instrumentos de planificación territorial y ambiental involucrados en una cuenca hidrográfica.

\subsection{La institucionalización y la norma como materialización del poder político del Estado}

Para analizar la coordinación entre instrumentos de planificación ambiental y territorial, a nivel de cuencas hidrográficas, es pertinente comprender el rol de la planificación como ejercicio de poder del Estado moderno en la organización y articulación de sus instituciones. En este sentido, desde la teoría crítica, el Estado, como órgano regulador de la vida social, ejerce el poder político, entendido como la capacidad de imponer decisiones o asegurar la obediencia por parte de la sociedad, a través de su acción coactiva (instrumentos persuasivos), y mediante la opresión o acción 
violenta cuando hay resistencia (Echeverri, 1980, citado por Bolaños, 2014). Por otra parte, Bobbio (2010, citado por Buitrago y Leal, 2012) menciona que el Estado ejerce poder mediante diversos medios para lograr el bien común. Aunque en el Estado moderno capitalista, dicho poder se concentra en clases dominantes, quienes lo emplean para alcanzar sus propios intereses, olvidando su dimensión social (Sassen, 2010; 2015).

Para Echeverri (1980), en el Estado subyace el concepto de política, considerada como una esfera particular de las relaciones entre clases, orientada a la conquista y mantenimiento del control del poder político. La política como práctica puede relacionarse con tres elementos básicos: el poder político; sus instrumentos, como por ejemplo organismos o aparatos mediante los cuales se materializa dicho poder (órganos legislativos, ejecutivos, administrativos, judicial); y, finalmente, organismos que permiten conquistar, controlar y conservar el poder político en manos de clases dominantes (partidos políticos u otras organizaciones) (Bolaños, 2014). En consecuencia, la política no solo se convierte en la acción del Estado, sino que también compete a todos los aspectos de interés social transcendentalmente públicos, como constituye el medio ambiente (López y Del Pozo, 1999, citado por Bolaños, 2014).

Asimismo, para ejercer su poder político, el Estado divide -cuando trata jurídicamente a cada individuo en su relación de poder- y homogeniza -cuando crea leyes para normalizar el comportamiento de las personas y tratar asuntos concernientes a él- (Buitrago y Leal, 2012; Sassen, 2010). Desde esta perspectiva, el Estado desarrolla una estructura administrativa en forma de red, única, para administrar el poder en la sociedad y el territorio (Castro, 2005, citado por Buitrago y Leal, 2012), compuesta por instituciones, garantes del cumplimiento de normas y leyes, así como el recaudo de impuestos para beneficio común. Con lo anterior, se considera que la gestión y planificación ambiental representan uno de los medios de poder, que el Estado capitalista tiene al momento de consolidarse territorial y políticamente.
Sin embargo, los agentes sociales, indistintamente del papel que desempeñan al interior del Estado, establecen relaciones de poder dinámicas, materializadas a través de complejas geografías, muchas desiguales ambientalmente (Sassen, 2015). En Colombia, por ejemplo, la modernización del Estado nacional favoreció la visibilización de agentes sociales ignorados históricamente del andamiaje social (Buitrago, 2015), permitiendo así su protagonismo en la esfera pública de pueblos indígenas y comunidades afrodescendientes, sobrevivientes a la barbarie colonizadora, quienes bajo principios históricos y culturales reclamaron derechos sobre tierras de propiedad colectiva (Buitrago, 2015), y dispusieron de instrumentos de planificación ambiental y sociocultural, cuyo propósito buscaba mejorar las condiciones de vida de sus comunidades $\sin$ detrimento de su cosmovisión.

No obstante, se resalta que estos instrumentos son determinantes en los procesos de planificación socioeconómica, ambiental y territorial del Estado, es decir, que cualquier instrumento o política estatal con incidencia espacial debe reconocer y garantizar la autonomía de comunidades indígenas y afrodescendientes sobre el territorio. Por esta razón, la planificación debe realizarse bajo principios de coordinación, articulación y concordancia, que para el caso de la cuenca del río Dagua es indispensable en los procesos de recuperación y mejoramiento de su calidad ambiental, de interés para los distintos agentes sociales y económicos involucrados en su planificación y gestión.

\subsection{Contexto de la planificación territorial y ambiental en Colombia en cuencas hidrográficas}

La Constitución Política de Colombia (CP), en el Artículo 288 de 1991, establece que las competencias atribuidas a diferentes niveles territoriales deben desarrollarse bajo principios de coordinación, concurrencia y subsidiaridad (Asamblea Nacional Constituyente, 1991). En relación al principio de coordinación, se mani- 
fiesta que este implica comunicación y articulación constante entre niveles territoriales, para armonizar aspectos vinculados al cumplimiento de metas sociales, económicas y ambientales. Considerando lo anterior, la Ley 99 de 1993, que organiza el Sistema Nacional Ambiental de Colombia, y dicta lineamientos generales para el manejo ambiental del país, a través del Artículo 63, donde expone el principio de armonía general, el cual plantea que las entidades territoriales, regionales, locales y de comunidades indígenas, deben ejercer funciones relacionadas con el medio ambiente y los recursos naturales renovables, de manera coordinada y armónica, siguiendo las directrices de la Política Nacional Ambiental, para garantizar su manejo articulado, racional y coherente (Congreso de la República de Colombia, 1993b).

Asimismo, la Ley 388 (Congreso de la República de Colombia, 1997) y la Ley 1454 (Congreso de la República de Colombia, 2011 ) establecen lineamientos generales para el ordenamiento territorial en Colombia y retoman el principio de coordinación en los Artículos 7 y 27 de la CP de 1991 (Asamblea Nacional Constituyente, 1991). De manera específica, La Ley 1454, conocida como Ley Orgánica del Ordenamiento Territorial (LOOT), menciona que la coordinación es un principio fundamental para el ejercicio de las competencias de entidades territoriales, debido a que promueve la articulación, coherencia y armonía entre estas, con el propósito de garantizar derechos ciudadanos y del medio ambiente (Congreso de la República de Colombia, 2011).

Igualmente, el Decreto 1640, que reglamenta instrumentos de planificación, ordenación y manejo de cuencas hidrográficas y acuíferos, establece en el Artículo 28 que la elaboración de Planes de Ordenamiento y Manejo de Cuencas debe considerar la armonización con otros instrumentos de planificación y/o manejo de recursos naturales renovables existentes, como son los planes de manejo de humedales, páramos, manglares, rondas hídricas, entre otros (Ministerio de Ambiente y Desarrollo Sostenible, 2012).

Este Decreto permite la creación de instancias de coordinación interinstitucional e intersectorial como es el Consejo Ambiental Regional, que opera a nivel de macrocuenca, y la Comisión Conjunta, para casos donde las cuencas hidrográficas sean de competencia de dos o más autoridades ambientales. Por lo tanto, los instrumentos de gestión ambiental, bien sea de tipo económico, tecnológico, de planificación, información, entre otros, disponibles para que las instituciones y entidades del Estado puedan materializar objetivos de desarrollo territorial sostenible, deben formularse bajo el principio de coordinación y articulación interinstitucional.

La articulación de estos instrumentos con procesos de gestión y planificación territorial adquiere relevancia con la promulgación de la CP de 1991, la cual tiene como principios la protección de riquezas naturales y culturales de la nación, descentralización de funciones del Estado, reconocimiento de la diversidad cultural y los procesos de participación ciudadana en la gestión pública (Asamblea Nacional Constituyente, 1991). En consecuencia, lo anterior es clave al momento de brindar soluciones a problemas socio-ambientales en cuencas hidrográficas, ya que permite garantizar la consolidación de condiciones de vida en todas las esferas del sistema hídrico.

Para alcanzar un sistema territorial sustentable, el Ordenamiento Territorial (OT), como instrumento de planificación, busca, a través del poder público del Estado, orientar y resolver conflictos espaciales, en beneficio del interés común, de forma participativa y concertada entre los agentes sociales involucrados, siempre con una visión a mediano y largo plazo (Goméz y Gómez, 2013). Lo cual es clave para la cuenca del río Dagua, en la medida en que la coordinación conjunta de sus instrumentos supramunicipales debe garantizar una gestión ambiental y espacial coordinada del recurso hídrico.

En Colombia, el OT, según Massiris (1998), es el resultado de la intervención espacial de políticas ambientales, económicas, sociales y culturales, así como del manejo político-administrativo del territorio nacional, que marca una estrecha relación entre ellas, y que, a largo 
plazo, orienta estrategias sectoriales del país. Desde esta perspectiva, debe existir una articulación entre instrumentos de planificación territorial y ambiental con los planes de desarrollo económicos y sociales (Bolaños, 2015).

Con base en lo anterior, el análisis de políticas relacionadas con: 1) el OT, regido por la Ley 1454 - Ley Orgánica para el Ordenamiento Territorial (Congreso de la República de Colombia, 2011)- y la Ley 388 -que permite la creación de Planes de Ordenamiento Territorial Municipales (Congreso de la República de Colombia, 1997)-; 2) el desarrollo económico y social a través de la Ley 152 -Ley Orgánica del Plan de Desarrollo (Congreso de la República de Colombia, 1994)-, y planes de vida y etnodesarrollo de comunidades indígenas y afrodescendientes promovidos por la CP de 1991; y 3) políticas de manejo y gestión de cuencas hidrográficas reglamentadas por el Decreto 1640 , que rige instrumentos de planificación, ordenación y manejo de cuencas hidrográficas y acuíferos (Ministerio de Ambiente y DesarroIlo Sostenible, 2012). En su conjunto, son claves en procesos de gestión ambiental y recursos hídricos a nivel nacional, regional y local, por su articulación y establecimiento de estrategias supramunicipales para el manejo integrado de cuencas hidrográficas, garantizando la recuperación y conservación de ecosistemas fundamentales para el desarrollo de la vida.

\section{Discusión y resultados}

A continuación, se describen tres elementos importantes asociados con la coordinación de instrumentos de gestión territorial en la cuenca del río Dagua: el primero, analiza estrategias de gestión ambiental y del recurso hídrico consideradas por entidades territoriales dentro sus planes a nivel individual. El segundo, identifica puntos de encuentro y tratamiento supramunicipal de dichas estrategias al interior de los planes, con el fin de analizar formas de articulación entre las distintas entidades territoriales (municipios), evidenciando al mismo tiempo la relación entre componentes generales de cada plan con el Plan de Gestión Ambiental Regional 2002-2012. Finalmente, se intenta comparar los lineamientos genera- les de los planes de vida y etnodesarrollo de comunidades indígenas y afrodescendientes, que orientan los consejos y resguardos ubicados en la cuenca del río Dagua, para analizar formas de articulación de sus visiones con los postulados supramunicipales en la cuenca.

\subsection{Planes de Ordenamiento Territorial pertinentes a la Cuenca Hidrográfica del río Dagua}

Los Planes de Ordenamiento Territorial (POT) son instrumentos de planificación que orientan el desarrollo territorial sustentable a nivel municipal en Colombia, a partir de la formulación y ejecución de objetivos, estrategias, políticas, programas y proyectos propuestos a corto, mediano y largo plazo. Sus componentes deben considerar el contexto regional y lineamientos generales propuestos en planes de gestión ambiental.

En este sentido, a nivel individual se identificó que los municipios establecen estrategias orientadas a la conservación, protección y restauración de recursos naturales, destacando sus cuencas hidrográficas, la definición de suelos de protección ambiental y el desarrollo de actividades de control, mitigación y vigilancia de contaminación del agua por actividades socio-económicas. También se resalta el mejoramiento en la prestación de servicios de acueducto y saneamiento básico, fundamentales para la reducción de impactos generados por la descarga directa de aguas residuales domésticas en afluentes del río Dagua. Del mismo modo, otro aspecto clave contemplado por municipios como La Cumbre y Restrepo son los programas de capacitación y educación ambiental con agentes sociales, gremios de agricultores e instituciones educativas. Lo anterior se sintetiza en la Tabla 1.

A nivel supramunicipal, se revisaron los componentes generales de los POT y su articulación entre ellos en relación a conservación y protección de recursos naturales y prestación de servicios públicos, pertinentes para el mejoramiento de condiciones ambientales 
de la cuenca, cuyos resultados evidenciaron formas precarias de articulación. Solo dos municipios contemplan articulación (ver Tabla 2).

Buenaventura, por su localización, es el municipio que afronta las acciones generadas en la parte alta de la cuenca. Contempla una planificación conjunta con los municipios de Dagua, La Cumbre y Restrepo. Del mismo modo, el Municipio de Restrepo ha propuesto acciones conjuntas para la protección y conservación ambiental de la cuenca. Por su parte, el Municipio de Dagua, pese a su localización estratégica entre Cali y Buenaventura, y tener la mayor área en la cuenca, no contempla acciones conjuntas con el resto de municipios en materia ambiental.
Los municipios de La Cumbre y Vijes, si bien no presentan acciones concretas para estos temas, sí consideran posibilidades de asociarse con municipios vecinos para resolver problemas ambientales comunes en torno a la cuenca. De esta forma, se evidencia un proceso de desarticulación en los componentes generales de los POTs, que fomentan problemas ambientales asociados a la cuenca, entre los cuales se resaltan: erosión del suelo debido al incremento de actividades agropecuarias en ladera, con repercusiones en el puerto de Buenaventura debido a procesos de colmatación; contaminación del agua por altos niveles de intervención humana y fragmentación de la propiedad rural. Lo anterior trae como consecuencia procesos de intervención territorial no acordes a la realidad espacial de la cuenca.

Tabla 1. Estrategias de gestión individual en POTs, cuenca del río Dagua

\begin{tabular}{|c|c|c|}
\hline Municipio & $\begin{array}{l}\text { Mejoramiento de servicios públicos de } \\
\text { acueducto y alcantarillado }\end{array}$ & Mejoramiento ambiental de la cuenca \\
\hline Buenaventura & $\begin{array}{c}\text { Regulación y tratamiento de aguas superficia- } \\
\text { les contaminadas }\end{array}$ & $\begin{array}{c}\text { Estudios hidrológicos para evaluación de } \\
\text { afectación del río Dagua por extracción de } \\
\text { material de arrastre } \\
\text { Planes de manejo y ordenamiento de cuencas } \\
\text { hidrográficas (recuperación y conservación de } \\
\text { recursos naturales y mitigación de amenazas } \\
\text { naturales) }\end{array}$ \\
\hline
\end{tabular}

\begin{tabular}{|c|c|c|}
\hline Dagua & $\begin{array}{l}\text { Mantenimiento de redes de acueducto y } \\
\text { alcantarillado } \\
\text { Construcción de Planta para aguas residuales }\end{array}$ & $\begin{array}{c}\text { Control y vigilancia de actividades económicas } \\
\text { Definición de suelos de protección }\end{array}$ \\
\hline La Cumbre & $\begin{array}{c}\text { Sistemas de medición de agua en acueductos } \\
\text { rurales }\end{array}$ & $\begin{array}{c}\text { Definir estructura ambiental municipal como } \\
\text { estrategia de conservación, recuperación y uso } \\
\text { sostenible de recursos naturales } \\
\text { Balances hídricos } \\
\text { Regulación de cultivos para producción limpia } \\
\text { Recuperación de suelos y agua mediante } \\
\text { conservación de coberturas vegetales }\end{array}$ \\
\hline Restrepo & Tratamiento de aguas residuales & $\begin{array}{c}\text { Implementar Plan de manejo de cuencas } \\
\text { hidrográficas } \\
\text { Recuperación y delimitación de microcuencas y } \\
\text { nacimientos de agua } \\
\text { Programas de educación ambiental y manejo } \\
\text { racional de productos agroquímicos }\end{array}$ \\
\hline Vijes & $\begin{array}{c}\text { Programas de saneamiento básico } \\
\text { Ampliación de cobertura de servicios públicos } \\
\text { domiciliarios }\end{array}$ & $\begin{array}{c}\text { Preservación de vegetación nativa, corredores } \\
\text { paisajísticos y fuentes hídricas } \\
\text { Desarrollo sostenible de actividades agrope- } \\
\text { cuarias y forestales } \\
\text { Estudios técnicos para inventario de flora y } \\
\text { fauna y recursos naturales }\end{array}$ \\
\hline \multicolumn{3}{|c|}{$\begin{array}{l}\text { Fuente: elaboración propia con base en Concejo Municipal de Buenaventura (2001; 2012); Concejo Municipal de Dagua } \\
\text { (2000; 2002); Concejo Municipal de La Cumbre (2015); Secretaría de Planeación de la Cumbre (2001); Alcaldía Municipal } \\
\text { de Restrepo (2015); Concejo Municipal de Vijes (2000); Alcaldía de Vijes (2015). }\end{array}$} \\
\hline
\end{tabular}


Sociedad y Economía N 43 (Mayo - Ago 2021) / e-ISSN: 2389-9050 / e1019207

Marco Antonio Aguirre, Oscar Buitrago-Bermúdez y Francy Viviana Bolaños-Tróchez

Tabla 2. Articulación de Planes de Ordenamiento Territorial municipales

\begin{tabular}{|c|c|c|c|c|c|}
\hline Municipios & Buenaventura 2001 & Dagua 2001 & Restrepo 1999 & La Cumbre 2001 & Vijes 2000 \\
\hline $\begin{array}{l}\text { Buenaventura } \\
2001\end{array}$ & $\Delta$ & \multicolumn{3}{|c|}{$\begin{array}{l}\text { Modelo Territorial Rural: alianzas estratégicas intermunicipales con } \\
\text { instituciones ambientales para su gestión ambiental. POT del Municipio } \\
\text { contempla: Conservación de recursos naturales; liderar con Dagua, La } \\
\text { Cumbre, Restrepo y la Autoridad Ambiental (Corporación Autónoma } \\
\text { Regional del Valle del Cauca CVC) acciones de control, protección y } \\
\text { mitigación ambiental sobre actividades económicas en la cuenca }\end{array}$} & $*$ \\
\hline Dagua 2001 & $*$ & $\Delta$ & $*$ & $*$ & $*$ \\
\hline Restrepo 1999 & * & $\begin{array}{c}\text { Ver La Cumbre-Cali- } \\
\text { ma Darién }\end{array}$ & $\Delta$ & $\begin{array}{l}\text { Asociación con } \\
\text { Dagua, Calima-Da- } \\
\text { rién y La Cumbre: } \\
\text { Plan de protección y } \\
\text { conservación de } \\
\text { sub-cuencas }\end{array}$ & $*$ \\
\hline La Cumbre 2001 & $*$ & $*$ & $*$ & $\Delta$ & * \\
\hline Vijes 2000 & $*$ & $*$ & $*$ & $*$ & $\Delta$ \\
\hline
\end{tabular}

Noła: * sin articulación; $\Delta$ no aplica.

Fuente: elaboración propia con base en Concejo Municipal de Buenaventura (2001; 2012); Concejo Municipal de Dagua (2000; 2002); Concejo Municipal de La Cumbre (2015); Secretaría de Planeación de la Cumbre (2001); Alcaldía Municipal de Restrepo (2015); Concejo Municipal de Vijes (2000); Alcaldía de Vijes (2015).

\subsection{Articulación de los POT con}

el Plan de Gestión Ambiental

Regional del Valle del Cauca (PGAR 2002 - 2012)

El Plan de Gestión Ambiental Regional -PGAR(Corporación Autónoma Regional del Valle del Cauca, 2012), reglamentado por el Decreto 1200 de 2004, es un "instrumento de planificación ambiental estratégica de largo plazo de las corporaciones autónomas regionales para el área de su jurisdicción, que permite orientar su gestión e integrar acciones de todos los actores" (Ministerio de Ambiente y Vivienda, 2004 , s.p.). Por tanto, las entidades territoriales deben considerar las líneas estratégicas de los PGAR en la formulación y ajuste de los POT y planes de desarrollo social y económico. En este sentido, se revisó la articulación de los POT municipales con el PGAR del departamento del Valle del Cauca, ya que estos instrumentos comprenden estrategias de intervención territorial a largo plazo y abarcan aproximadamente tres periodos de gobierno municipal (12 años) que, a su vez, deben ser incorporados en los Planes de Desarrollo.

De esta forma, las líneas estratégicas del PGAR 2002-2012 son tres: coordinación interinstitucional, participación y concertación comunitaria, y educación ambiental para el fortalecimien- to de canales de comunicación e información. A continuación, se analiza la articulación de dichas líneas con los POT (ver Tabla 3).

Con este ejercicio se observa cómo gran parte de los municipios de la cuenca contempló en sus POT programas y/o proyectos en relación con algunos lineamientos del PGAR; solo el municipio de Vijes guarda diferencias con las líneas estratégicas, específicamente en lo que respecta a la coordinación interinstitucional y fortalecimiento de canales de comunicación e información, lo cual puede interferir en la articulación del municipio con su ámbito regional inmediato, aspecto que se concibe en su Esquema de Ordenamiento Territorial (EOT).

\subsection{Planes de Desarrollo (Ley 152 de 1994)}

La Ley 152 establece procedimientos y mecanismos para la elaboración, aprobación, ejecución, seguimiento, evaluación y control de planes de desarrollo a nivel municipal, departamental y nacional (Congreso de la República de Colombia, 1994). Dichos planes comprenden un conjunto de objetivos, metas, estrategias, programas y proyectos formulados a mediano y largo plazo, según sean los resultados del diagnóstico general de las condiciones económicas, sociales y ambientales del 
Sociedad y Economía N 43 (Mayo - Ago 2021) / e-ISSN: 2389-9050 / e1019207 Mecanismos de coordinación en la planificación de cuencas hidrográficas en Colombia: el caso del río Dagua

Tabla 3. Ajuste de los POT municipales en la cuenca con el PGAR 2002-2012

\begin{tabular}{|c|c|c|c|c|c|}
\hline $\begin{array}{l}\text { Líneas } \\
\text { estratégicas del } \\
\text { PGAR }\end{array}$ & Buenaventura 2001 & Dagua 2001 & Restrepo 1999 & La Cumbre 2001 & Vijes 2000 \\
\hline $\begin{array}{l}\text { Coordinación } \\
\text { interinstitucional }\end{array}$ & $\begin{array}{c}\text { Alianzas } \\
\text { intermunicipales } \\
\text { con instituciones } \\
\text { públicas y } \\
\text { privadas } \\
\text { nacionales, } \\
\text { departamentales } \\
\text { e internacionales } \\
\text { para gestión } \\
\text { ambiental }\end{array}$ & $\begin{array}{c}\text { Convenios } \\
\text { interadministrati- } \\
\text { vos de coopera- } \\
\text { ción y desarrollo } \\
\text { regional } \\
\text { ambiental con } \\
\text { municipios, } \\
\text { organismos } \\
\text { gubernamenta- } \\
\text { les, regionales y } \\
\text { nacionales }\end{array}$ & $\begin{array}{c}\text { Asociación } \\
\text { interinstitucional } \\
\text { entre municipios, } \\
\text { autoridades } \\
\text { ambientales y } \\
\text { secretarías de } \\
\text { agricultura para } \\
\text { manejo de } \\
\text { ecosistemas }\end{array}$ & $\begin{array}{l}\text { Articulación entre } \\
\text { empresas } \\
\text { prestadoras de } \\
\text { servicios públicos } \\
\text { y comunidades } \\
\text { para mejora- } \\
\text { miento en su } \\
\text { prestación }\end{array}$ & Sin coordinación \\
\hline $\begin{array}{l}\text { Participación y } \\
\text { concertación } \\
\text { comunitaria }\end{array}$ & $\begin{array}{l}\text { Concertación con } \\
\text { comunidades } \\
\text { indígenas y } \\
\text { afrodescendien- } \\
\text { tes para mitigar } \\
\text { degradación de } \\
\text { recursos } \\
\text { naturales }\end{array}$ & $\begin{array}{l}\text { Coordinación y } \\
\text { participación } \\
\text { ciudadana para } \\
\text { gestión del agua }\end{array}$ & $\begin{array}{c}\text { Participación } \\
\text { comunitaria en } \\
\text { temas ambienta- } \\
\text { les }\end{array}$ & $\begin{array}{l}\text { Participación } \\
\text { comunitaria en } \\
\text { procesos de } \\
\text { planificación del } \\
\text { agua }\end{array}$ & $\begin{array}{l}\text { Participación } \\
\text { ciudadana para } \\
\text { control sobre } \\
\text { decisiones } \\
\text { ambientales }\end{array}$ \\
\hline $\begin{array}{l}\text { Educación } \\
\text { ambiental }\end{array}$ & $\begin{array}{l}\text { Creación de } \\
\text { centros de } \\
\text { educación } \\
\text { ambiental y } \\
\text { protección de } \\
\text { zonas forestales }\end{array}$ & $\begin{array}{c}\text { Educación } \\
\text { ambiental como } \\
\text { prioridad de la } \\
\text { gestión ambien- } \\
\text { tal }\end{array}$ & $\begin{array}{c}\text { Educación } \\
\text { ambiental para } \\
\text { conservación y } \\
\text { recuperación de } \\
\text { recursos } \\
\text { naturales y } \\
\text { disposición de } \\
\text { residuos sólidos y } \\
\text { líquidos }\end{array}$ & $\begin{array}{l}\text { Implementar } \\
\text { centro de } \\
\text { educación } \\
\text { ambiental y } \\
\text { programas de } \\
\text { protección de la } \\
\text { cuenca }\end{array}$ & $\begin{array}{l}\text { Conservar } \\
\text { recursos } \\
\text { naturales } \\
\text { mediante } \\
\text { participación } \\
\text { comunitaria }\end{array}$ \\
\hline $\begin{array}{l}\text { Fuente: elab } \\
\text { (2000; 2002); }\end{array}$ & $\begin{array}{l}\text { ncejo Municipal de } \\
\text { de Restrepo ( } 2\end{array}$ & $\begin{array}{l}\text { Concejo Municip } \\
\text { Cumbre (2015); } \\
\text {; Concejo Municip }\end{array}$ & $\begin{array}{l}\text { ría de Planea } \\
\text { Vijes (2000); }\end{array}$ & $\begin{array}{l}2012) \text {; Concejo } \\
\text { la Cumbre }(200 \\
\text { a de Vijes }(2015)\end{array}$ & $\begin{array}{l}\text { ipal de Dagua } \\
\text { caldía Municipal }\end{array}$ \\
\hline
\end{tabular}

territorio. En el ámbito municipal, su formulación debe articularse a contenidos y reglamentaciones propuestas en los planes o programas desarrollados para la gestión ambiental, así como para el ordenamiento territorial, bajo criterios que posibiliten estimar costos y beneficios ambientales al momento de definir acciones, para garantizar a las actuales y futuras generaciones una oferta ambiental adecuada.

En esta perspectiva, primero se analizarán los Planes de Desarrollo (PD) a nivel nacional y departamental, con el propósito de identificar elementos de coordinación entre sus objetivos y estrategias relacionados con la gestión ambiental y del recurso hídrico (ver Tabla 4). Posteriormente, se exponen las estrategias de los PD municipales a nivel individual (ver Tabla 5) y se interpretan las formas de articulación entre municipios con jurisdicción en la cuenca hidrográfica del río Dagua (ver Tabla 6).

Como se observa en la Tabla 4, el PD del Valle del Cauca 2012 - 2015, se articula con los objetivos propuestos en el Plan Nacional de Desarrollo
2014 - 2018 en temas asociados al fomento del desarrollo sostenible, conservación y protección del medio ambiente, consolidación de la economía regional y el bienestar social; así como en el desarrollo de estrategias de conservación y aprovechamiento sostenible de recursos naturales, y mejoramiento en la prestación de servicios de agua y saneamiento básico (Departamento Nacional de Planeación, 2012). Estos se articulan a las estrategias de crecimiento, protección y uso sostenible del capital natural contenidos en el PND, el cual se presenta bajo un enfoque de crecimiento verde como estrategia de desarrollo económico, para lograr el bienestar social de la población en el largo plazo, garantizando disponibilidad y conservación de bienes y servicios ambientales para las actuales y futuras generaciones (Departamento Nacional de Planeación, 2012).

Desde otra perspectiva, los PD Municipales pertinentes a la cuenca del río Dagua, para el periodo 2012-2015, se caracterizan por la inclusión de estrategias de gestión ambiental y servicios públicos que, además de seguir los lineamientos traza- 
Tabla 4. Coordinación entre PND y PDD relacionados con la gestión ambiental y del recurso hídrico PND 2014 - 2018 "Todos por un nuevo país" PDD del Valle del Cauca 2012 - 2015 "Vallecaucanos, hagámoslo bien"

Propone crecimiento sostenible y bajo en carbono a partir
de tres aspectos:
1) Transformación de sectores económicos con eficiencia y
manejo del agua
2) Mejoramiento de la gestión sectorial: reducción de
mercurio en procesos mineros (mitigar impactos ambienta-
les en la salud humana)
3) Mejorar tratamiento de aguas residuales y reciclaje de
residuos sólidos

Afianzar procesos de planificación y ordenamiento territorial a partir de:

1) Promoción de minería con tecnologías verdes y sostenibles

2) Control de minera ilegal

3) Implementación de políticas departamentales sostenibles

4) Construcción de eco-viviendas

Abastecimiento de agua potable y condiciones de saneamiento básico a partir de:

1) Capacitación para el manejo de recursos naturales, residuos sólidos y peligrosos

2) Monitoreo de recursos financieros en sector agua $y$ saneamiento

3) Vinculación de municipios al Plan Departamental de Agua e implementación del Plan de Gestión Social de Agua Potable y Saneamiento Básico para la región 4) Programa "cultura del agua" para comunidades indígenas y afrocolombianas

5) Rehabilitación de infraestructura y prestación eficiente de servicios públicos con esquemas regionales

6) Fortalecimiento a empresas prestadoras de servicios públicos en implementación de Planes de Saneamiento y Manejo de Vertimientos, Planes de Ahorro y Uso Eficiente del Agua y Planes de Gestión Integral de Residuos Sólidos

\footnotetext{
Conservación de calidad ambiental mediante:

1) Uso sostenible de áreas protegidas

2) Ordenamiento territorial sostenible

3) Fomento de sectores productivos, mercados verdes, uso eficiente del agua, tecnologías de producción limpias y proyectos de biotecnología y bio-prospección

4) Consolidación política de cambio climático
}

Conservación y aprovechamiento de biodiversidad y recursos hídricos:

1) Inversión para conservación y recuperación de áreas naturales, cuencas hidrográficas y mitigación del riesgo

2) Gestión de un CONPES* para el río Dagua, con el fin de recuperar la cuenca y reducir la sedimentación que afecta el puerto de Buenaventura

3) Protección y recuperación de cuencas en el departamento, a través de coordinación interinstitucional

4) Agricultura sustentable y ecológica

5) Creación de zonas protectoras de biodiversidad y recursos naturales

6) Campañas de prevención y cuidado del agua y ambiente

7) Protección del conocimiento ancestral de suelo y agua en comunidades étnicas

Nota: * Consejo Nacional de Política Económica y Social: máxima autoridad nacional de planeación. Se desempeña como organismo asesor del Gobierno nacional en materia económica.

Fuente: elaboración propia a partir de Asamblea Departamental del Valle del Cauca (2012) y Congreso de la República de Colombia (2015).

dos a nivel nacional y departamental, comprenden aspectos claves en el mejoramiento de la cuenca a partir de apuestas individuales (véase Tabla 5). Con lo anterior, se encontró que los cinco municipios concuerdan en dos aspectos claves: el primero, con la conservación y aprovechamiento de recursos naturales, haciendo énfasis en el agua, especialmente el municipio de Buenaventura al que, por su localización estratégica en el Chocó Biogeográfico, se le atribuyen altos niveles de precipitación y diversidad en flora y fauna. Segundo, con el mejoramiento y ampliación de la prestación de servicios públicos de agua y saneamiento básico, los cuales, a nivel individual, mitigarían la contaminación asociada a descarga de aguas residuales en afluentes hídricos (Corporación Autónoma Regional del Valle del Cauca y Fundación Pangea, 2005).

Con respecto a la educación ambiental como estrategia para fomentar el desarrollo sustentable, esta solo es concebida por los municipios de Buenaventura y Vijes, los cuales orientan sus estrategias al ma- 


\section{Tabla 5. Objetivos y estrategias en PD Municipales: cuenca del río Dagua entre 2012-2015}

\begin{tabular}{|c|c|c|c|}
\hline & Ámbito & Objetivos & Estrategias \\
\hline \multirow{5}{*}{ Buenaventura } & \multirow[t]{4}{*}{ MA } & Educación ambiental & Campañas uso y manejo racional del agua \\
\hline & & Ordenamiento sustentable de cuencas hidrográficas & Plan de ordenamiento y manejo de la cuenca \\
\hline & & Uso sostenible de recursos naturales & Plan de Manejo Minero Ambiental de subcuencas \\
\hline & & Fomento de ecoturismo sostenible & Implantación de rutas turísticas del agua \\
\hline & SP & Prestación eficaz de servicios públicos domiciliarios & $\begin{array}{l}\text { Mejoramiento en cobertura de servicios de agua } \\
\text { potable y saneamiento básico }\end{array}$ \\
\hline \multirow{9}{*}{ Dagua } & \multirow{5}{*}{ MA } & \multirow{5}{*}{ Conservación y protección de recursos naturales } & $\begin{array}{l}\text { Formulación e implementación de planes de manejo } \\
\text { de cuencas }\end{array}$ \\
\hline & & & Seguimiento a usuarios de recursos naturales \\
\hline & & & $\begin{array}{l}\text { Programas de reducción de riesgos por cambio } \\
\text { climático y gestión integral del agua }\end{array}$ \\
\hline & & & Fortalecer organizaciones ambientales y educativas \\
\hline & & & $\begin{array}{l}\text { Protección del paisaje natural y control de tráfico } \\
\text { ilegal de flora y fauna }\end{array}$ \\
\hline & \multirow{4}{*}{ SP } & \multirow{4}{*}{$\begin{array}{l}\text { Mejorar las condiciones de abastecimiento y } \\
\text { calidad de agua y recolección, tratamiento y } \\
\text { disposición final de residuos sólidos y líquidos }\end{array}$} & $\begin{array}{l}\text { Garantizar cobertura de abastecimiento de agua } \\
\text { potable }\end{array}$ \\
\hline & & & $\begin{array}{l}\text { Ajustar plan de gestión integral de residuos sólidos a } \\
\text { las necesidades existentes }\end{array}$ \\
\hline & & & $\begin{array}{l}\text { Promover educación ambiental para tratamiento y } \\
\text { manejo de aguas domésticas y disposición de } \\
\text { residuos sólidos }\end{array}$ \\
\hline & & & $\begin{array}{l}\text { Métodos alternativos para prestación de servicios de } \\
\text { agua y saneamiento }\end{array}$ \\
\hline \multirow{9}{*}{ La Cumbre } & \multirow{5}{*}{ MA } & \multirow{5}{*}{$\begin{array}{l}\text { Recuperar, conservar y proteger recursos } \\
\text { naturales }\end{array}$} & $\begin{array}{l}\text { Recuperación, mantenimiento y/o conservación de } \\
\text { fuentes y áreas de recarga acuífera }\end{array}$ \\
\hline & & & Reglamentación uso del suelo \\
\hline & & & Mitigación del cambio climático \\
\hline & & & $\begin{array}{l}\text { Diagnóstico, evaluación y control de condiciones } \\
\text { ecosistémicas de cuencas hidrográficas }\end{array}$ \\
\hline & & & Educación y cultura ambiental \\
\hline & \multirow{4}{*}{ SP } & \multirow{4}{*}{$\begin{array}{l}\text { Mejorar prestación y acceso a servicios públicos } \\
\text { domiciliarios }\end{array}$} & $\begin{array}{l}\text { Garantizar cobertura de agua potable y } \\
\text { saneamiento básico }\end{array}$ \\
\hline & & & $\begin{array}{l}\text { Implementar Planes de Gestión Integral de Residuos } \\
\text { Sólidos }\end{array}$ \\
\hline & & & Fortalecer Juntas de acueductos rurales \\
\hline & & & $\begin{array}{l}\text { Creación de un fondo de solidaridad y redistribución } \\
\text { de ingresos en servicios públicos domiciliarios }\end{array}$ \\
\hline \multirow{2}{*}{ Restrepo } & \multirow{2}{*}{ MA y SP } & \multirow{2}{*}{$\begin{array}{l}\text { Garantizar calidad ambiental a través de } \\
\text { normas de protección del aire, agua y suelo }\end{array}$} & $\begin{array}{l}\text { Incrementar calidad del servicio de acueducto e } \\
\text { implementar el plan maestro de alcantarillado }\end{array}$ \\
\hline & & & $\begin{array}{l}\text { Mejorar tratamiento de aguas residuales, recolección } \\
\text { y manejo de residuos sólidos }\end{array}$ \\
\hline \multirow{5}{*}{ Vijes } & \multirow{3}{*}{ MA } & $\begin{array}{l}\text { Acciones de manejo y aprovechamiento de } \\
\text { fuentes hídricas }\end{array}$ & Recuperación de fuentes hídricas \\
\hline & & $\begin{array}{l}\text { Acciones de conservación y preservación del } \\
\text { suelo }\end{array}$ & $\begin{array}{l}\text { Cumplimiento de la norma para recuperar zonas } \\
\text { ambientalmente degradadas }\end{array}$ \\
\hline & & $\begin{array}{l}\text { Actividades de vigilancia y control de contamina- } \\
\text { ción ambiental }\end{array}$ & Educación ambiental \\
\hline & \multirow[t]{2}{*}{ SP } & $\begin{array}{l}\text { Mejorar saneamiento básico y cobertura en } \\
\text { suministro de agua }\end{array}$ & $\begin{array}{l}\text { Garantizar la cobertura y calidad del agua } \\
\text { optimizando acueductos y reposición y mejoramiento } \\
\text { de sistemas sépticos }\end{array}$ \\
\hline & & Fortalecer sistema de aseo rural & $\begin{array}{l}\text { Acciones de tratamiento de escombros y residuos } \\
\text { sólidos }\end{array}$ \\
\hline
\end{tabular}

Noła: MA: Manejo Ambiental; SP: Servicios Públicos.

Fuente: elaboración propia a partir de Corporación Autónoma Regional del Valle del Cauca (2012); Concejo Municipal de Buenaventura (2001; 2012); Concejo Municipal de Dagua (2000; 2002); Concejo Municipal de La Cumbre (2015); Secretaría de Planeación de la Cumbre (2001); Alcaldía Municipal de Restrepo (2015); Concejo Municipal de Vijes (2000); Alcaldía de Vijes (2015). 
Tabla 6. Coordinación entre PD Municipales con la visión de las comunidades étnicas

\begin{tabular}{|c|c|c|c|c|c|}
\hline Municipios & Buenaventura & Dagua & Restrepo & La Cumbre & Vijes \\
\hline Buenaventura & $\Delta$ & $*$ & \multicolumn{2}{|c|}{$\begin{array}{l}\text { Los Planes de Desarrollo tienen como } \\
\text { meta la formulación del plan de manejo } \\
\text { de la cuenca del río Dagua, en armonía } \\
\text { con los municipios de La Cumbre, } \\
\text { Restrepo y Vijes (cuenca alta) y la } \\
\text { participación de CVC, comunidades } \\
\text { étnicas y el Ministerio del Medio } \\
\text { Ambiente. }\end{array}$} & $*$ \\
\hline Dagua & $*$ & $\Delta$ & $*$ & $*$ & $*$ \\
\hline Restrepo & $*$ & $*$ & $\Delta$ & $*$ & $*$ \\
\hline La Cumbre & $*$ & $*$ & $*$ & $\Delta$ & $*$ \\
\hline Vijes & * & $*$ & * & $*$ & $\Delta$ \\
\hline
\end{tabular}

Nota: * sin visión; $\Delta$ no aplica.

Fuente: elaboración propia a partir de Concejo Municipal de Buenaventura (2012); Consejo Municipal de Dagua (2013); Concejo Municipal de La Cumbre (2015); Concejo Municipal de Vijes (2013).

nejo y aprovechamiento sostenible de recursos naturales, e implementan una cultura ambiental, mediante la participación ciudadana. Finalmente, es importante destacar que, en la parte alta de la cuenca, solo Vijes propone control a los procesos erosivos del suelo, lo cual constituye una de las principales problemáticas ambientales que afectan a la bahía del puerto marítimo de Buenaventura.

Al analizar el nivel de coordinación entre políticas, programas y proyectos de gobierno en torno a la protección y conservación de recursos naturales y mejoramiento en la prestación de servicios públicos, que íntegramente mejoran las condiciones de la cuenca del río Dagua, se encontró que solo el Municipio de Buenaventura mantiene una concepción de ciudad-región. De manera opuesta, el resto de municipios continúan desarrollando estrategias individuales que no garantizan un trabajo articulado y eficiente de gestión ambiental y del recurso hídrico (ver Tabla 6). En la Figura 2 y la Figura 3 se puede contrastar la no coordinación de instrumentos de gestión supramunicipales acordes con la realidad ambiental en la cuenca.

\subsection{Instrumentos de planificación social, económica y territorial de comunidades ancestrales. Caso de la cuenca del río Dagua}

En Colombia, la Constitución Política de 1991 (CP), en su Artículo 7, reconoce y protege la diversidad étnica y cultural de la Nación, permitien- do la creación de figuras territoriales colectivas, ancestrales e inajenables de comunidades étnicas para salvaguardar y garantizar sus prácticas culturales, de las cuales se destacan los resguardos indígenas y territorios colectivos de comunidades afrodescendientes (Asamblea Nacional Constituyente, 1991). A continuación, se describe cada una de ellas con el fin de observar si existe coordinación entre sus posturas y la gestión integrada de la cuenca del río Dagua y el agua.

Para los grupos indígenas, la CP establece que "la conformación de entidades territoriales indígenas se hará con sujeción a lo dispuesto en la Ley Orgánica de Ordenamiento Territorial (LOOT), y su delimitación se hará por el Gobierno Nacional, con participación de representantes de comunidades indígenas, previo concepto de la Comisión de Ordenamiento Territorial" (Asamblea Nacional Constituyente, 1991, Art. 329). Aunque el reconocimiento del territorio de pueblos indígenas queda expreso en la CP de 1991, solo hasta el año 2014 se expide en Colombia el Decreto 1953 de 2014, en el cual se "pone en funcionamiento los Territorios Indígenas respecto de la administración de los sistemas propios de pueblos indígenas" (Ministerio del Interior, 2014).

Por otro lado, para las comunidades afrodescendientes, la titulación de tierras, aunque no fue reglamentada directamente por la CP de 1991, sí se realizó a través del Artículo transitorio 55, que dio paso a la formulación de la Ley 70 del 27 de agosto de 1993. La Ley 
Sociedad y Economía N 43 (Mayo - Ago 2021) / e-ISSN: 2389-9050 / e1019207

Mecanismos de coordinación en la planificación de cuencas hidrográficas en Colombia: el caso del río Dagua

Figura 2. Monocultivos de pino y eucalipto, deforestación, erosión del suelo y ganadería en ladera. Municipio de Dagua

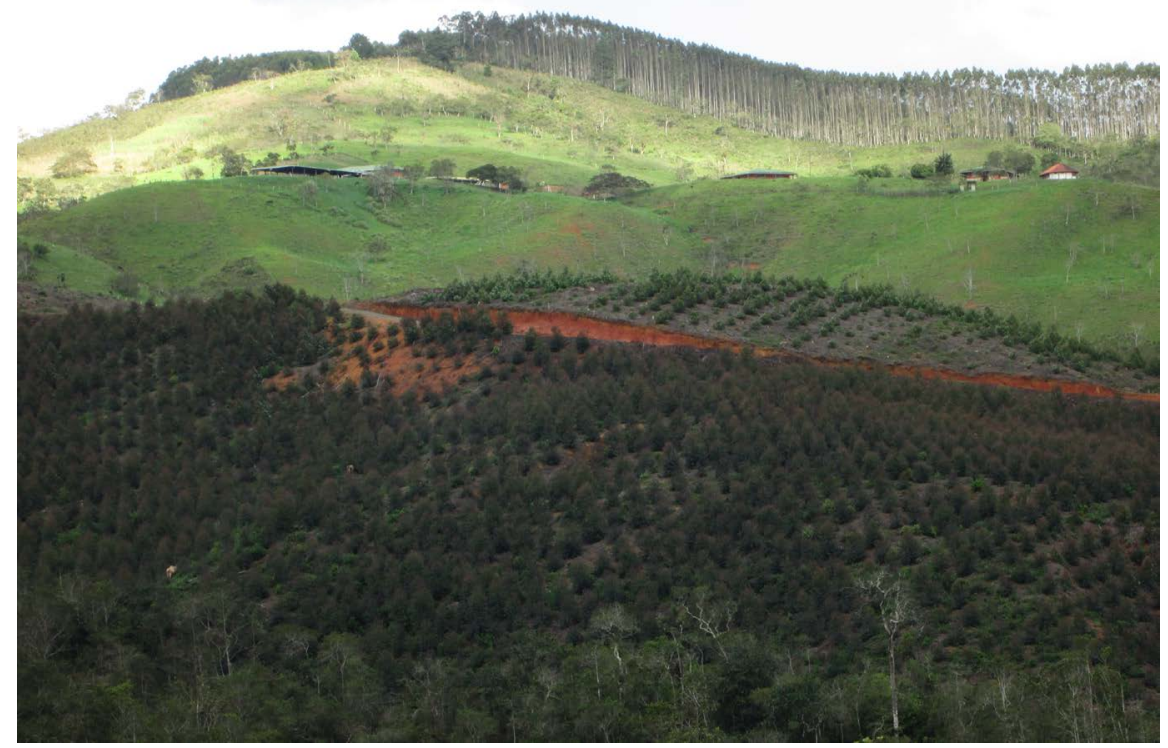

Fuente: fotografía tomada por el equipo de trabajo, agosto de 2017.

Figura 3. Vertimiento de aguas domésticas y residuos a fuentes de agua. Municipio de La Cumbre

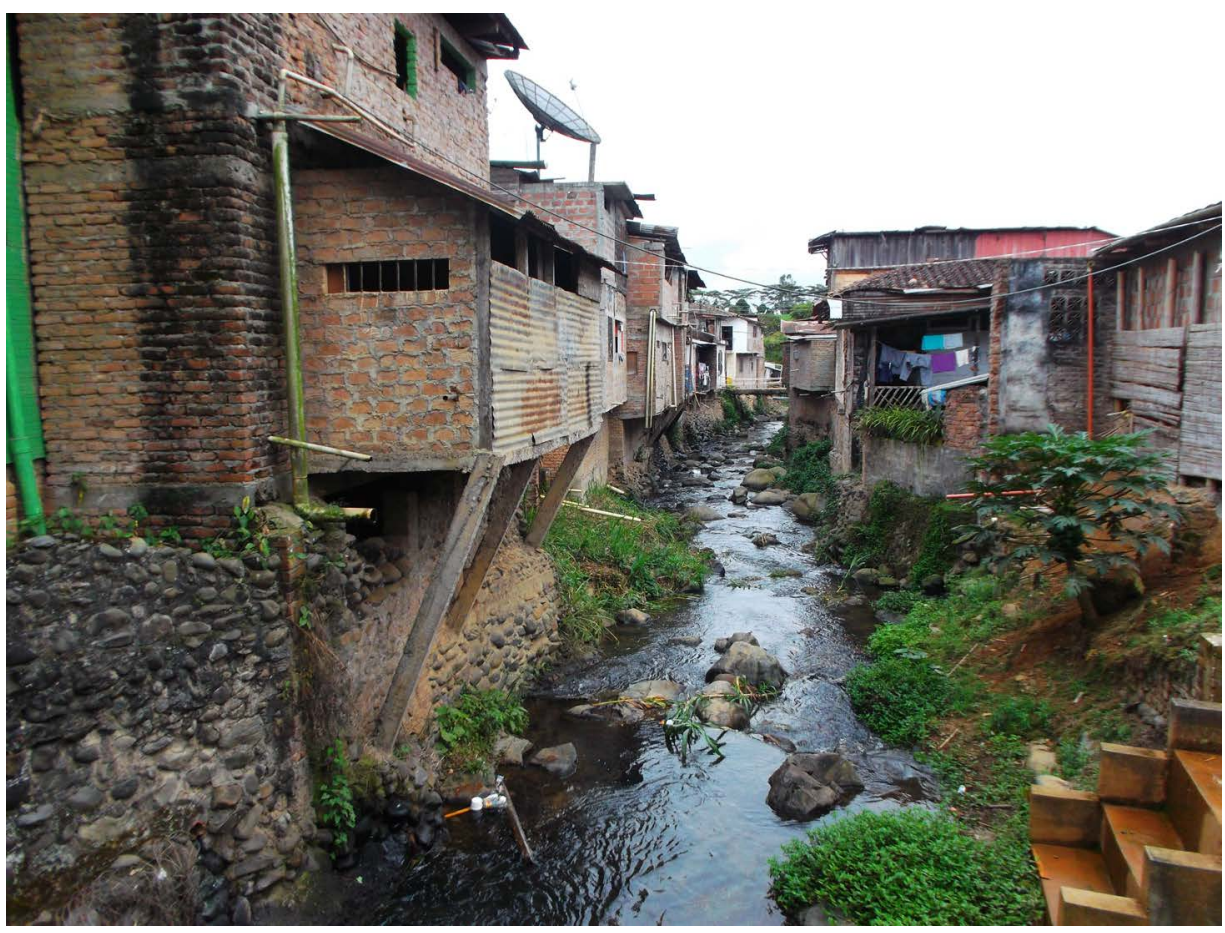

Fuente: fotografía tomada por el equipo de trabajo, agosto de 2017. 
reconocía y reglamentaba el derecho a la propiedad colectiva de comunidades negras, orientando a la ocupación de tierras baldías en zonas rurales ribereñas de ríos de la cuenca del Pacífico colombiano (Congreso de la República de Colombia, 1993a). Desde esta perspectiva, tanto pueblos indígenas como comunidades afrodescendientes, en su condición de pueblos diversos, cuentan con planes de vida de orden comunitario que integran su cosmovisión, la cual debe articularse a los POT a nivel municipal.

En la parte baja de la cuenca del río Dagua conviven comunidades afrodescendientes y pueblos indígenas. Cada uno posee instrumentos de organización territorial, que en algunos casos convergen para lograr un desarrollo integral de sus comunidades, y en otros, divergen por sus cosmovisiones frente al agua y su territorio. En ese contexto, la Tabla 6 sintetiza la forma en la cual los instrumentos del Estado (principalmente PD municipales) integran en sus lineamientos las visiones de las comunidades étnicas en la cuenca. No obstante, se percibe que el Estado, a través de sus instrumentos, no reconoce la visión de las comunidades. Para una mayor claridad normativa de comunidades ancestrales en Colombia en torno a la toma de decisiones territoriales, se presenta la Tabla 7.

El contenido del Plan depende del contexto de cada comunidad u organización indígena y quedan explícitas una serie de demandas con respecto a educación, salud, infraestructura, etc. Además del ejercicio del Ordenamiento Territorial, que es fundamental para construir la autonomía de sus pueblos, el plan define relaciones entre miembros de la comunidad con actores externos, especialmente para el manejo de recursos colectivos como el agua y el suelo.

Para las comunidades afrodescendientes dichos planes son: Planes de Manejo Ambiental de Comunidades Afrodescendientes y Etnodesarrollo. Los primeros son instrumentos de planeación que tienen los consejos comunitarios o comunidades negras para la administración de sus territorios colectivos. Estos tienen un enfoque orientado a la productividad y gestión del territorio, el cual se desarrolla en aso-

Tabla 7. Dimensión territorial de comunidades ancestrales en la normatividad colombiana

\begin{tabular}{lll}
\multicolumn{1}{c}{ Ley orgánica } & \multicolumn{1}{c}{ Pueblos indígenas } & \multicolumn{1}{c}{ Comunidades afrodescendientes } \\
\hline $\begin{array}{l}\text { Constitución Política } \\
\text { de } 1991\end{array}$ & $\begin{array}{l}\text { (Art. 329) reconoce conformación de entidades } \\
\text { territoriales indígenas concebidas como resguardos } \\
\text { de propiedad colectiva no enajenable }\end{array}$ & $\begin{array}{l}\text { (Art. Transitorio 55) reconoce el territorio de } \\
\text { comunidades negras, quienes históricamente han } \\
\text { ocupado tierras baldías en zonas rurales ribereñas } \\
\text { de ríos en la Cuenca del Pacífico, garantizando sus } \\
\text { prácticas tradicionales de producción y el derecho } \\
\text { a la propiedad colectiva }\end{array}$ \\
& $\begin{array}{ll}\text { Facilita el diseño de políticas, planes y programas } \\
\text { de desarrollo económico y social del territorio }\end{array}$ & $\begin{array}{l}\text { Propone a las comunidades Planes de Manejo y } \\
\text { colectivo de pueblos indígenas, reconociéndolos } \\
\text { como entidades territoriales junto a departamen- } \\
\text { tos, distritos y municipios }\end{array}$
\end{tabular}

\begin{tabular}{ll}
\hline Ley 152 de 1994: & El Estado define que los pueblos indígenas deben \\
Ley Orgánica de & formular sus propias políticas de desarrollo social \\
Plan de Desarrollo & y económicas
\end{tabular}

Ley Orgánica de

Plan de Desarrolio

\begin{abstract}
formular sus propias políticas de desarrollo social y económicas
\end{abstract}

(Art. 3) establece en los principios rectores del ordenamiento territorial la multietnicidad (principio 17), con la cual "los pueblos indígenas, comunidades afrodescendientes, raizales y población ROM ejercen su derecho de planeación y gestión dentro de entidades territoriales"

\begin{tabular}{ll}
\hline Decreto 1953 de & Crea régimen especial para funcionamiento de \\
2014 & $\begin{array}{l}\text { Territorios Indígenas. Estado legitima los derechos } \\
\text { a terceros que disponen de tierras en propiedad } \\
\text { de predios indígenas }\end{array}$ \\
\hline
\end{tabular}

Ley 70 de 1993
Reconoce las Comunidades Negras como grupos étnicos con diferentes formas de apropiación del territorio y sistemas tradicionales de organización y producción y reconoce territorios colectivos y prácticas ancestrales 
cio con el Ministerio de Medio Ambiente como institución que representa al Estado. También parten del diagnóstico ambiental del territorio para identificar debilidades y potencialidades; así mismo, caracterizan prácticas ancestrales de las comunidades en relación con el territorio.

En segunda instancia, los Planes de Etnodesarrollo se convierten en el principal mecanismo de planeación de los grupos étnicos para formular propuestas de solución a corto, mediano y largo plazo. Generalmente comprenden líneas estratégicas, campos de acción y dimensiones o sectores hacía los cuales se dirigirán los programas o proyectos. Con base en lo anterior, se realiza una comparación de los lineamientos generales de los planes de comunidades indígenas y afrodescendientes, con el fin de identificar puntos de encuentro entre ambas visiones, que permitan articular acciones colectivas en pro de la gestión ambiental del agua en la cuenca del río Dagua (tal como se observa en la Tabla 8 ).

Como se puede analizar, ambas comunidades consideran clave en sus planes la preservación del territorio ancestral, así como la identidad cultural y la autonomía. El planteamiento de los principales elementos, se realiza de manera participativa, aunque su proyección en el tiempo para resolver aspectos puntuales difie- re entre ambas comunidades: por un lado, las comunidades afrodescendientes conciben sus acciones en el mediano y largo plazo y, por otro lado, las comunidades indígenas planean dichas acciones a largo plazo. Es importante destacar que, debido a la falta de disponibilidad de Planes de Vida, Etnodesarrollo y de Manejo Ambiental asociados a la cuenca hidrográfica del río Dagua, no fue posible identificar cómo dichos planes se articulan a los procesos de gestión ambiental supramunicipales propuestos en la cuenca, lo cual es necesario desarrollar en estudios posteriores.

\section{Conclusiones}

La investigación permite evidenciar tres elementos clave para abordar la hipótesis central en la cual la articulación entre instrumentos de gestión ambiental, a nivel municipal, no responde a las actuales condiciones ambientales de la cuenca. En ese sentido, primeramente, se percibe que -pese a los diversos mecanismos de intervención y control del Estado como agente territorial en la cuenca del río Daguano se logra establecer un lenguaje en común entre los cinco municipios de mayor presencia espacial en la cuenca. Por otro lado, las evidencias académicas de autores como Aguirre et al. (2017), Universidad del Valle (2016; 2017), Gamboa (2018), López y González (2016), Tangarife y Villaquirá (2016), Rojas y Campo

Tabla 8. Puntos de encuentro de las visiones de comunidades ancestrales en la cuenca hidrográfica del río Dagua

\begin{tabular}{|c|c|c|c|}
\hline Componentes & Planes de Etnodesarrollo & Planes de Manejo & Planes de Vida \\
\hline Grupo étnico & Afrocolombianos & Afrocolombianos & Indígenas \\
\hline Duración & Mediano y largo plazo & Mediano y corto plazo & Largo plazo y permanente \\
\hline Beneficiarios & $\begin{array}{l}\text { Comunidades } \\
\text { afrodescendientes }\end{array}$ & $\begin{array}{l}\text { Comunidades } \\
\text { afrodescendientes }\end{array}$ & Pueblos indígenas \\
\hline $\begin{array}{l}\text { Metodología de } \\
\text { formulación }\end{array}$ & Colectiva y participativa & Colectiva y participativa & Colectiva y participativa \\
\hline Temáticas & $\begin{array}{c}\text { - Contexto de la comunidad } \\
\text { afrocolombiana } \\
\text { - Ancestralidad } \\
\text { - Autonomía } \\
\text { - Sistemas tradicionales y } \\
\text { saberes } \\
\text { - Actividades productivas de la } \\
\text { comunidad } \\
\text { - Territorio } \\
\text { - Colectividad } \\
\text { - Perspectiva de vida }\end{array}$ & $\begin{array}{c}\text { - Contexto de la comunidad } \\
\text { afrocolombiana } \\
\text { - Ancestralidad } \\
\text { - Autonomía } \\
\text { - Sistemas tradicionales } \\
\text { (agropecuario, minero, etc.) } \\
\text { - Características físicas del } \\
\text { territorio }\end{array}$ & $\begin{array}{l}\text { - Territorio } \\
\text { - Autonomía } \\
\text { - Cultura } \\
\text { - Espiritualidad }\end{array}$ \\
\hline \multicolumn{4}{|c|}{ Fuente: elaboración propia a partir de las entrevistas en campo. } \\
\hline
\end{tabular}


(2018), Corporación Autónoma Regional del Valle del Cauca y Fundación Pangea (2005) y Álvarez (2019) demuestran espacialmente que las condiciones ambientales de la cuenca hidrográfica no son las más sustentables.

Un tercer aspecto clave de la investigación se sustenta en la no cooperación municipal para atender la planificación y gestión ambiental de la cuenca de manera integral. Ello se traduce en la no correspondencia entre los postulados de los Planes de Desarrollo Municipales y Planes de Ordenamiento Territorial con las necesidades ambientales de la cuenca. A esto se suma la no incorporación en sus propuestas de las visiones de comunidades étnicas, las cuales tienen una significativa presencia espacial en la geografía de la cuenca. Aunque a nivel individual se contemplan acciones orientadas a la protección del ambiente y de recursos naturales mediante la definición de suelos de protección, entre los cuales se incorporan áreas que comprenden determinantes de ordenamiento territorial como constituye la Reserva Forestal Protectora y Distritos de Manejo y conservación de suelos y agua, ello no constituye una garantía para la restauración integral del ecosistema de la cuenca.

Esta situación se reinterpreta a través de las distintas entrevistas puntuales con agentes sociales claves en la cuenca, a través de las cuales fue posible conocer que no ha existido voluntad política entre los entes administrativos municipales para concretar el Plan de Manejo y Gestión Ambiental de la cuenca. Al respecto, la Corporación Autónoma Regional del Valle del Cauca -CVC- ha liderado acercamientos políticos entre las partes y algunos miembros de las comunidades étnicas con el fin de consolidar los primeros pasos de dicho Plan. A la fecha, la voluntad política a nivel municipal de las administraciones no ha dado frutos.

Pese a lo anterior, se debe reconocer que existe una intención de coordinación de gestión de la cuenca por parte del municipio de Buenaventura, localizado en la parte baja de la cuenca, con el propósito de mejorar las condiciones ambientales y reducir los procesos de erosión del suelo que afectan el nivel base de sedimentación del principal puerto marítimo de Colombia, ubicado en el Océano Pacífico. Pese a dicha iniciativa, en la actualidad no existen grados de correspondencia en los procesos de planificación de Buenaventura y los municipios que integran la parte alta de la cuenca, quienes aceleran los procesos de erosión del suelo a través del desarrollo de sus actividades económicas y productivas y, a la vez, afectan las condiciones ambientales del agua (Aguirre et al., 2017; Universidad del Valle, 2017).

En síntesis, se observa que la planificación territorial a nivel supramunicipal constituye una debilidad para garantizar acciones contundentes en pro de la conservación y mejoramiento integral de la cuenca, así como de los procesos de gestión ambiental y del agua. Por lo cual, es necesario definir y priorizar acciones conjuntas a nivel municipal que incidan en la cuenca y reduzcan espacialmente los problemas citados en el texto. Este proceso se puede realizar bien sea a través del Plan de Ordenamiento y Manejo de la cuenca -que en la actualidad no existe- o por medio del Plan de Gestión Ambiental Regional (PGAR), con la participación activa de organizaciones sociales y la inclusión de comunidades ancestrales asentadas en la cuenca.

\section{Referencias}

Aguirre, M., López, L., Bolaños, F., González, D. y Buitrago, O. (2017). Percepción del paisaje, agua y ecosistemas en la cuenca del río Dagua, Valle del Cauca, Colombia. Perspectiva Geográfica, 22(1), 109126. https://doi.org/10.19053/01233769.5402

Alcaldía de Vijes. (2015). Plan de desarrollo municipal de Vijes "Para Vijes lo mejor" 2012 - 2015. Alcaldía de Vijes.

Alcaldía Municipal de Restrepo. (2015). Plan de desarrollo municipal de Restrepo "Porque la prosperidad para Restrepo se construye entre todos 2012 - 2015". 2012. Alcaldía Municipal de Restrepo. 
Álvarez, L. (2019). Elaboración de un sistema de biomonitoreo de la calidad del agua en el río Dagua (tesis de maestría). Universidad del Valle, Cali, Colombia.

Álvarez-Gayou, J. (2012). Cómo hacer investigación cualitativa. Fundamentos y metodología. Editorial Paidós.

Asamblea Departamental del Valle del Cauca. (2012). Ordenanza 356 de 2012 "El Valle vale". Secretaría General; Gobernación del Valle del Cauca.

Asamblea Nacional Constituyente. (1991). Constitución Política de Colombia. http://www.alcaldiabogota. gov.co/sisjur/normas/Normal.jsp?i=4125

Bolaños, F. (2014). La gestión del agua potable como hecho metropolitano. Caso: Corredor metropolitano Cali-Yumbo (tesis de pregrado). Universidad del Valle.

Bolaños, F. (2015). Marco normativo de la gestión pública del agua potable en Colombia y su contribución en los procesos de integración territorial metropolitana. Entorno geográfico, (11), 140-152. https://doi. org/10.25100/eg.v0i11.3669

Buitrago, O. (2015). Territorialidades silenciadas. El papel de etnias, estado y capitalistas en la producción de los territorios colombianos (Documento inédito). Universidad del Valle.

Buitrago, O. (2016). Competitividad territorial capitalista y despojo del agua en el área de influencia metropolitana de Cali (Colombia). Cuadernos de Geografía, 25(2), 237-250. https://doi.org/10.15446/ rcdg.v25n2.54719

Buitrago, O. y Leal, C. (2012). Poder político, território e crise ambiental na Colômbia. Finisterra, 47(93), 129-142. https://doi.org/10.18055/Finis 1301

Buitrago, O., Aguirre, M y Bolaños, F. (2019). La percepción social del agua como indicador de salud ambiental en una Cuenca Hidrográfica: Cuenca del Río Dagua, Colombia. En R. Borges-Guimarães, L. Seolin-Dias y S. Seolin-Dias (Orgs.), Ambiente e Saúde: pensar, aplicar e agir (pp. 103-129). ANAP.

Cáceres, P. (2003). Análisis cualitativo de contenido: una alternativa metodológica alcanzable. Revista Psicoperspectiva, 2(1), 53-82. https://doi.org/10.5027/psicoperspectivas-vol2-issue 1-fulltext-3

Congreso de la República de Colombia. (1993a). Ley 70 de 1993. Desarrolla el artículo transitorio 55 de la Constitución Política de 1991. DO No. 41013. http://www.suin-juriscol.gov.co/viewDocument. asp?ruta=Leyes $/ 1620332$

Congreso de la República de Colombia. (1993b). Ley 99. DO No. 41146 . http://www.secretariasenado.gov. co/senado/basedoc/ley_0099_1993.html

Congreso de la República de Colombia. (1994). Ley 152 de 1994. Ley Orgánica del Plan del Desarrollo. DO No. 41.450. https://www.funcionpublica.gov.co/eva/gestornormativo/norma.php?i=327

Congreso de la República de Colombia. (1997). Ley 388 de 1997. Ley de Ordenamiento Territorial. DO No. 43.091. http://www.secretariasenado.gov.co/senado/basedoc/ley_0388_1997.html

Congreso de la República de Colombia. (2011). Ley 1454 de 2011 . Ley Orgánica de Ordenamiento Territorial. DO No. 48.115. http://www.secretariasenado.gov.co/senado/basedoc/ley_1454_2011.html

Congreso de la República de Colombia. (2015). Ley 1753 por la cual se expide el Plan Nacional de Desarrollo 2014 - 2018 "Todos por un nuevo país". https://colaboracion.dnp.gov.co/CDT/Normograma/Ley\%20 1753\%20de\%202015.pdf

Concejo Municipal de Buenaventura. (2001). Acuerdo 03 de 2001, por el cual se aprueba el Plan de ordenamiento territorial para el municipio de Buenaventura 2001 -2013. Alcaldía de Buenaventura.

Concejo Municipal de Buenaventura. (2012). Acuerdo 05 de 2012 por el cual se aprueba el Plan de desarrollo distrital de Buenaventura "Progreso en marcha" 2012-2015. Alcaldía de Buenaventura. 
Concejo Municipal de Dagua. (2000). Decreto No 955 de mayo del 2000, por el cual el municipio de Dagua adopta los lineamientos del PBOT. Alcaldía del municipio de Dagua.

Concejo Municipal de Dagua. (2002). Acuerdo 004 del 28 de mayo de 2002, por el cual se aprueba el Plan básico de ordenamiento territorial para el municipio de Dagua "Dagua Pacifico" 2001-2010. Alcaldía del municipio de Dagua.

Concejo Municipal de Dagua. (2013). Acuerdo 010 del 31 de mayo de 2012, por el cual se aprueba el Plan de desarrollo municipal de Dagua "Mi Dagua con visión de futuro y libre de pobreza extrema" 2012 - 2015. Alcaldía del municipio de Dagua.

Concejo Municipal de La Cumbre. (2015). Plan de desarrollo municipal de La Cumbre "Primero lo social" 2012 - 2015 . Alcaldía del municipio de La Cumbre.

Concejo Municipal de Vijes. (2000). Acuerdo 054 de 2000 por el cual se aprueba el Esquema de ordenamiento territorial para el municipio de Vijes 2000 - 2010. Alcaldía del municipio de Vijes.

Concejo Municipal de Vijes. (2013). Plan de Desarrollo del Municipio de Vijes. Alcaldía del municipio de Vijes.

Corporación Autónoma Regional del Valle del Cauca. (2012). Plan de Gestión Ambiental Regional del Valle del Cauca 2012 - 2015. Corporación Autónoma Regional del Valle.

Corporación Autónoma Regional del Valle del Cauca. (s.f.). Portal de datos geográficos abiertos. https://geo. cvc.gov.co/arcgis/apps/sites/\#/datosabiertos

Corporación Autónoma Regional del Valle del Cauca y Fundación Pangea. (2005). Convenio 179-2005: Identificación de estrategias para la conservación del ecosistema enclave subxerofítico y su zona de influencia en el marco de áreas protegidas (resolución de conflictos) a través de procesos de concertación y realizar investigaciones participativas que determinen el potencial productivo de la flora propia del enclave subxerofítico de Dagua (Informe final). CVC.

DNP -Departamento Nacional de Planeación-. (2012). Ley 1450 por la cual se expide el Plan Nacional de Desarrollo 2010-2014 "prosperidad para todos". https://www.dnp.gov.co/Plan-Nacional-de-Desarrollo/ PND-2010-2014/Paginas/Plan-Nacional-De-2010-2014.aspx

Echeverri, A. (1980). Teoría constitucional y ciencia política: el Poder, el Estado, los Regímenes y las formas de Gobierno. Fondo de Publicaciones Fundación Educacional Autónoma de Colombia.

Gamboa, H. (2018). Estimación del índice de riesgo ecológico (IRE) del ecosistema fluvial de la cuenca del río Dagua (tesis de maestría). Universidad del Valle.

Gómez, D. y Gómez, A. (2013). Ordenación territorial (3 Ed). Mundi-Prensa.

Létourneau, J. (2009). La caja de herramientas del joven investigador: Guía de iniciación al trabajo intelectual. La Carreta Editores.

López, L. y González, D. (2016). Percepción del paisaje y los ecosistemas en la cuenca hidrográfica del río Dagua (tesis de pregrado). Universidad del Valle.

Massiris, A. (1998). Determinantes de los planes de ordenamiento territorial. Perspectiva Geográfica, (2) 7-70.

Ministerio de Ambiente y Desarrollo Sostenible. (2012). Decreto 1640. Instrumentos para la planificación, ordenación y manejo de las cuencas hidrográficas y acuíferos, y otras disposiciones. DO No. 48.510. https://www.minambiente.gov.co/images/normativa/decretos/2012/dec_1640_2012.pdf

Ministerio de Ambiente y Vivienda (2004). Decreto 1200. DO No. 41395. http://www.ideam.gov.co/ documents/51310/536020/Decreto+1200+de+2004.pdf/6c173cld-7bc3-49bc-a6cf-04539795b482

Ministerio del Interior. (2014). Decreto 1953 de 2014. Por el cual se crea un régimen especial con el fin de poner en funcionamiento los Territorios Indígenas. DO No. 49.297. https://www.funcionpublica.gov.co/ eva/gestornormativo/norma.php?i=59636 
Rojas, A. y Campo, L. (2018). Valoración de la calidad del agua a partir de la visión de agentes sociales en la cuenca hidrográfica del río Dagua. Entorno Geográfico, (16), 50-79. https://doi.org/10.25100/ eg.v0i16.7148

Sassen, S. (2010). Descolonización de las políticas estatales y privatización de la producción de normas. En G. Teubner, S. Sassen y S. Krasner (Eds.), Estado, Soberanía y Globalización (pp. 103-135). Editorial Universidad de los Andes.

Sassen, S. (2015). Una sociología de la globalización. Kast Editores.

Secretaría de Planeación de la Cumbre. (2001). Esquema de ordenamiento territorial para el municipio de La Cumbre 2001 - 2009. Alcaldía del municipio de La Cumbre.

Tangarife, M. y Villaquirá, Y. (2016). Paisaje y agua: el sentir de las comunidades asentadas en la cuenca baja del río Dagua (tesis de pregrado). Universidad del Valle.

Universidad del Valle. (2016). Informe Proyecto de Investigación Estrategias para la Recuperación y Manejo Integrado del Recurso Hídrico en las Cuencas del Cauca y Dagua, en el Valle del Cauca (Documento inédito). Universidad del Valle.

Universidad del Valle. (2017). Informe diagnóstico de la gestión del agua en la cuenca del río Dagua: Proyecto de Investigación Estrategias para la Recuperación y Manejo Integrado del Recurso Hídrico en las Cuencas del Cauca y Dagua (Documento inédito). Universidad del Valle. Documento inédito. 